\title{
A Step-up Approach for Cell Therapy in Stroke: Translational Hurdles of Bone Marrow-Derived Stem Cells
}

\author{
Loren E. Glover • Naoki Tajiri • Nathan L. Weinbren • \\ Hiroto Ishikawa $\cdot$ Kazutaka Shinozuka $\cdot$ Yuji Kaneko • \\ D. Martin Watterson - Cesar V. Borlongan
}

Received: 27 August 2011 /Revised: 29 September 2011 /Accepted: 21 October 2011 /Published online: 18 November 2011

(C) The Author(s) 2011. This article is published with open access at Springerlink.com

\begin{abstract}
Stroke remains a significant unmet condition in the USA and throughout the world. To date, only approximately $3 \%$ of the population suffering an ischemic stroke benefit from the thrombolytic drug tissue plasminogen activator, largely due to the drug's narrow therapeutic window. The last decade has witnessed extensive laboratory studies suggesting the therapeutic potential of cell-based therapy for stroke. Limited clinical trials of cell therapy in stroke patients are currently being pursued. Bone marrow-derived stem cells are an attractive, novel transplantable cell source for stroke. There remain many unanswered questions in the laboratory before cell therapy can be optimized for transplantation in the clinical setting. Here, we discuss the various translational hurdles encountered in bringing cell therapy from the laboratory to the clinic, using stem cell therapeutics as an emerging paradigm for stroke as a guiding principle. In particular, we focus on the preclinical studies of cell transplantation in experimental stroke with emphasis on a better understanding of mechanisms of action in an effort to optimize efficacy and to build a safety profile for advancing cell therapy to the clinic. A forward looking strategy of combination therapy involving stem cell transplantation and pharmacologic treatment is also discussed.
\end{abstract}

\footnotetext{
L. E. Glover $\cdot$ N. Tajiri $\cdot$ N. L. Weinbren $\cdot$ H. Ishikawa

K. Shinozuka $\cdot$ Y. Kaneko $\cdot$ C. V. Borlongan $(\bowtie)$

Department of Neurosurgery and Brain Repair,

University of South Florida College of Medicine, 12901 Bruce B. Downs Blvd,

Tampa, FL 33612, USA

e-mail: cborlong@health.usf.edu

D. M. Watterson $(\square)$

Department of Molecular Pharmacology and Biological

Chemistry,

Northwestern University Feinberg School of Medicine,

Chicago, IL 60611, USA

e-mail: m-watterson@northwestern.edu
}

Keywords Stroke · Endothelial progenitor cells · Cell therapy Drug treatment . Translational research

\section{Introduction}

Stroke continues to be a major cause of death in the USA and throughout the world. Due to treatment options for stroke being limited to tissue plasminogen activator (tPA), a surge in novel therapies, such as stem cell transplantation, has been explored in the laboratory. Over the last decade, stem cell therapy has shown promise as an experimental treatment for stroke [1-3]. The first clinical trial implementing cell therapy as a treatment for stroke occurred in 1998 [4]. In the last 2 years, the US Food and Drug Administration (FDA) has approved limited clinical trials of cell therapy in stroke patients. Bone marrow-derived stem and progenitor cells represent a major donor cell source for transplantation. Along the lines of stroke treatment academic industry roundtable (STAIR) recommendations for translating pharmacologics from the laboratory to the clinic, the stem cell therapeutics as an emerging paradigm for stroke (STEPS) has been advanced as a guiding principle for cell therapy in stroke. Here, we discuss preclinical studies of cell transplantation in experimental stroke with emphasis on bone marrow-derived stem cells using STEPS as a yardstick in building the efficacy and safety profile of this cell therapy for clinical application.

\section{The Many Faces of Bone Marrow-Derived Stem Cells}

The bone marrow consists of a heterogeneous population of stem cells, namely hematopoietic stem cells (HSCs) and 
mesenchymal stem cells (MSCs) [5]. Endothelial progenitor cells (EPCs) and very small embryonic-like stem cells (VSELs) have also been isolated from the bone marrow. Previous studies have discussed the potential of bone marrow-derived stem cells to differentiate into neurons in vitro [6], and their secretion of growth factors crucial to neuronal survival [7-9]. Interest in utilizing bone marrowderived stem cells as a therapy for stroke has increased as researchers look to cell therapy as a treatment for stroke.

A central characteristic of HSCs is their ability to repopulate removed bone marrow [10]. HSCs remain quiescent and low in number during homeostasis, but can quickly proliferate and become mobile in response to injury [11-13]. The SDF-1/CXCR4 chemoattractant pathway is crucial for HSC mobilization and migration. Activation of this pathway stimulates the migration of HSCs from the bone marrow into the circulation [14].

Mesenchymal stem cells were first defined as a population of plastic-adherent fibroblastic cells isolated by Percoll density centrifugation [15]. Human MSCs do not express the hematopoietic surface markers CD34 and CD45, but they do express CD13, Stro-1, CD105 (SH2), and SH3. The therapeutic potential of MSCs lies in their ability to differentiate into mesodermal lineages, such as skeletal myoblasts, fibroblasts, osteoblasts, adipocytes, and chondroblasts both in vitro and in vivo [16-20] (Table 1). MSCs utilized in experimental stroke models have improved the functional recovery of neurological deficits caused by cerebral ischemia [49-58]. Clinical reports of MSC transplantation in stroke patients reveal that MSCs may improve the functional recovery of patients without adverse side effects [49]. The underlying therapeutic mechanism through which MSCs offer therapeutic benefit remains unclear.
Very small embryonic-like cells are present in many adult organs expressing progenitor stem cell markers [46]. The brain contains a relatively high number of cells that display the VSEL phenotype $[47,59]$. VSELs are smaller than erythrocytes and can be purified from umbilical cord blood and mobilized peripheral blood. VSELs are recognized as very small cells belonging to the non-hematopoietic portion of leukocytes, expressing CD34, CD133, and CXCR4 antigens $[46,48]$ and are mobilized into the peripheral blood following injury.

EPCs are immature endothelial cells circulating in the peripheral blood. EPCs are an important component of the vascular system, as they mature into endothelial cells [2125]. Asahara and colleagues transplanted EPCs isolated from human umbilical cord blood into animal models of ischemia. The transplanted EPCs were found in the endothelium of newly formed vessels in the ischemic regions [21]. EPCs are hematopoietic in origin and can be found in the peripheral blood of adults and can also be isolated from human umbilical cord blood [60, 61]. Both animal and human studies suggest that EPCs principally participate in re-endothelialization during the neovascularization of ischemic organs. These findings suggest that EPC modulation can be focused toward the therapy of cerebrovascular diseases [21, 22, 25, 26, 61, 62] (Table 1).

HSCs, MSCs, and VSELs can all be categorized as donor cells primarily aimed toward rescuing the stroke damaged cells and ischemic cells within the parenchyma. While rescuing the ischemic penumbra is important, these cells do not address the issue of the damaged microvasculature. To this end, EPCs are unique in that they target the leaky vasculature. By repairing the broken blood brain barrier (BBB), EPCs may aid in the recovery from stroke and abrogate the immunological attack on the brain and its

Table 1 Target diseases and phenotypes of EPCs, MSCs, hTERT-MSCs, HSCs, and VSEL cells

\begin{tabular}{|c|c|c|c|}
\hline BM cells & Target disease & Phenotype & References \\
\hline EPCs & $\begin{array}{l}\text { Retinal ischemia, Parkinson's disease, malignant tumors, chronic obstructive, pulmonary } \\
\text { disease, ischemic stroke, traumatic brain injury, and Alzheimer's disease }\end{array}$ & Endothelial cells & {$[21-31]$} \\
\hline \multirow[t]{6}{*}{ MSCs } & \multirow{6}{*}{$\begin{array}{l}\text { Malignant tumors and cancer, inflammation, autoimmune, asthma, neurological damage } \\
\text { and regeneration (stroke, Alzheimer, Parkinson, traumatic brain injury, spinal cord } \\
\text { injury), cardiac-related disease (i.e., ischemic cardiomyopathy, myocardial infarction), } \\
\text { inflammatory bowel, multiple sclerosis, and liver regeneration }\end{array}$} & OCA cells & {$[32-35]$} \\
\hline & & OCA cells & {$[36,37]$} \\
\hline & & OCA cells & {$[18]$} \\
\hline & & OCA cells & [38-40] \\
\hline & & OCA cells & {$[41,42]$} \\
\hline & & OCA cells & {$[43-45]$} \\
\hline hTERT-MSCs & Cerebral ischemia and spinal cord injury & OCA cells & {$[42]$} \\
\hline HSCs & $\begin{array}{l}\text { Alzheimer's disease, traumatic brain injury, myeloid leukemia, sickle cell anemia, } \\
\text { and cutaneous repair }\end{array}$ & CD34+ and CXCR4+ & {$[10-13]$} \\
\hline VSEL Cells & Tissue rejuvenation, stroke, myocardial infractions, diabetes, and cutaneous repair & Tree germ lineages & {$[46-48]$} \\
\hline
\end{tabular}

OCA cells osteogenic, chondrogenic, and adipogenic cells 
microvasculature (Fig. 1). Due to their ability to differentiate into endothelial cells, EPCs may be the ideal choice for cell transplantation in BBB repair.

Due to laboratory findings suggesting the angiogenic and vasculogenic potential of EPCs, clinical studies have been initiated to determine if patients with ischemic events may benefit from EPC administration [63]. Studies have also been initiated to determine if patients with lower numbers of EPCs are at an increased risk of atherosclerotic events. Here, we discuss the therapeutic potential of EPCs, as well as the hurdles faced when translating EPC therapy from the laboratory to the clinic.

\section{Crossing the Great Divide: Cell Therapy at the Crossroad of Laboratory and Clinic}

Our team together with stem cell-based stakeholders from academic and industry, as well as federal agencies such as $\mathrm{NIH}$ and FDA, has supported the STEPS consortium in an effort to improve the successful translation of cell therapy in stroke from the laboratory to the clinic [3]. Both clinicians and researchers acknowledge that no two strokes are the same, underscoring the heterogeneity of the disease. Although ischemic stroke is the target of cell therapy over hemorrhagic stroke, ischemic stroke is plagued with several subtypes ranging from infarcted brain areas to cell death mechanisms. Only recently have laboratory studies attempted to encompass these various strokes in animal models [64]. The most commonly used model for stroke is focal ischemia in rats or mice. The cell death pathways and damaged brain regions after focal ischemia can be manipulated by using permanent, transient, proximal, or distal occlusion/ligation of the middle cerebral artery. In an effort to study the heterogeneity of stroke, multiple strains, age, gender, varying stroke severity, and at least two focal ischemia models should be utilized in the laboratory to test the safety and efficacy of cell therapy $[1,3]$. Testing cell therapy in a larger, non-human primate model may be needed due to the white matter injury associated with stroke [3, 65-67], which is not well characterized in the rodent model (Fig. 2). Other transplantation regimen issues, such as donor cell size which may cause microembolism, and toxicology readouts which may be better studied in a nonhuman primate model, may similarly necessitate testing of cell therapy in large animal model.

Route of administration is also an important factor that needs to be taken into consideration when translating cell therapy from the laboratory to the clinic. Although intravenous (IV) cell delivery is a minimally invasive procedure, it is traditionally only employed in acute stroke models, limiting the population that may benefit from cell therapy. IV cell transplantation requires a higher cell dose, which may cause the formation of microembolisms. Intraarterial (IA) cell delivery is also minimally invasive, but is typically only employed in acute stroke models to take advantage of the stroke-induced upregulation of chemoattractant pathways that aid in the migration of stem cells from the periphery to the brain. IA cell delivery may circumvent the formation of microembolisms by requiring a lower cell dose. Intracerebral (IC) cell transplantation can be employed in both the acute and chronic stages of stroke. However, IC cell delivery is an invasive procedure that requires a neurological surgery service, limiting the acute stroke patient population that would have access to this type of cell transplantation.

\section{Better Safe than Sorry: Safety Profile of Stem Cells}

In addition to demonstration of efficacy via behavioral testing, building a safety profile is an equally important
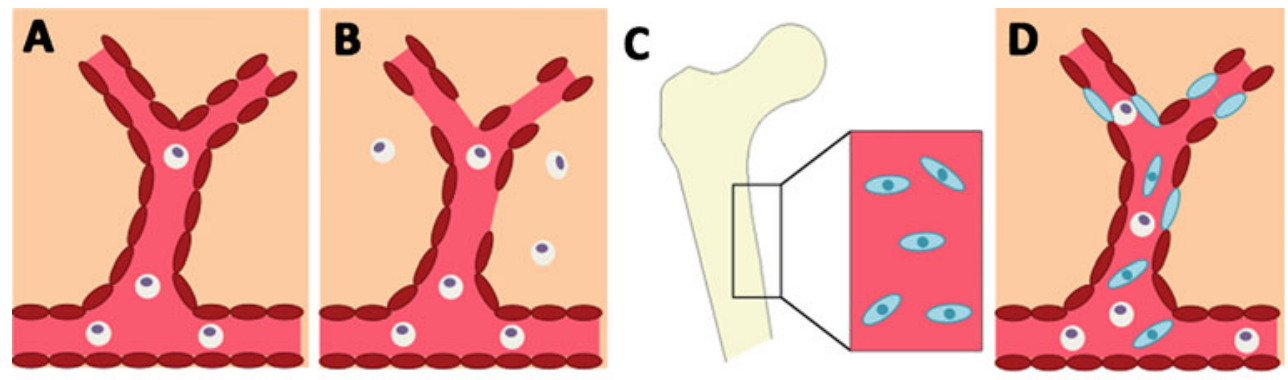

= Immune Cells

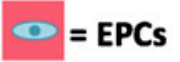

Fig. 1 BBB repair via EPC transplantation post-ischemic injury. Under normal conditions, the BBB is intact (a). The integrity of the BBB becomes compromised after stroke, allowing immune cells to enter the brain parenchyma (b). EPCs migrate from the periphery to the site of injury (c). Once at the area of injured vasculature, the EPCs aid in repairing the compromised $\mathrm{BBB}$, potentially attenuating stroke pathogenesis (d) 
Fig. 2 Translational steps from the laboratory to the clinic. Two focal ischemia models in rodents should be utilized to determine optimal timing, dose, and route of administration. Functional recovery should also be tested in the rodent models. Once these factors have been established in the rodent models, the cell therapy may require further validation in a larger animal model, especially when critical stroke readouts (e.g., white matter) cannot be determined in the rodents. Limited clinical trials may proceed in tandem with the preclinical studies once safety profile and efficacy outcomes are demonstrated in the laboratory

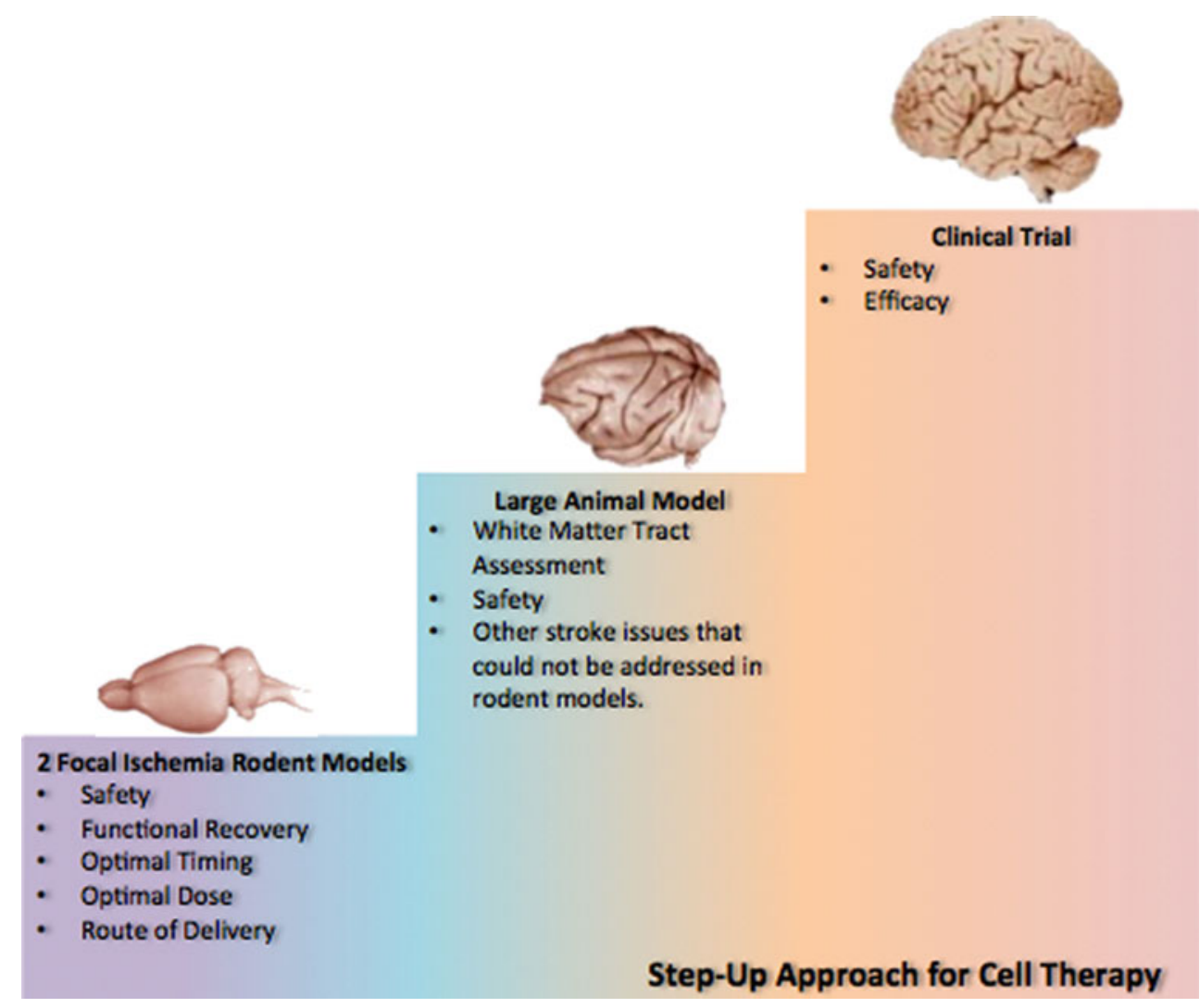

gating item prior to proceeding to clinical trials of stem cell therapy. Along this line, EPCs have had a recent history of safety in the clinic. Clinical studies have been initiated to determine whether patients with lower numbers of EPCs are at an increased risk of atherosclerotic events, and whether patients with ischemic events may benefit from EPC administration [68]. To date, clinical studies support the therapeutic potential of EPC transplantation; however, this assumption should be approached with much caution due to these studies being open label trials, observational and/or anecdotal accounts, and a limited number of patients.

Clinical studies of EPC in neurovascular disease are much very limited, with only three observational studies in patients with stroke. In 25 patients with an ischemic stroke, CD34+ cells peaked 7 days after stroke but generally reverted to baseline after 30 days [69]. Interestingly, higher CD34+ cell levels at 30 days related to an increased number of infarcts on magnetic resonance imaging and also to worse cerebrovascular function, as measured with positron emission tomography scanning (cerebral metabolic rate of oxygen, and cerebral blood flow). On the other hand, decreased numbers of clusters of rapidly adhering cells were seen after stroke and in "stable cerebrovascular disease," compared with controls free of vascular disease [24]. Cerebrovascular disease and higher age, in general, independently related to lower EPC numbers. These discrepancies in results may be from mismatched controls for patient age and/or the lack of methodological design for testing specific hypotheses on the causal role of EPC in cerebrovascular disease [24].

\section{The Changing Landscape of Cell-Based Therapeutic Targets: Intraparenchymal Versus Extraparenchymal Rescue of the Stroke Brain}

A major STEPS requirement is to demonstrate a specific set of phenotypic markers unique to the stem cell under investigation [3]. EPCs were first isolated from human peripheral blood and express shared markers with HSCs, angioblasts, and receptors for vascular endothelial growth factor (VEGFR2/KDR) [21]. Immunological surface markers and functional profiling via colony formation capacity have been utilized to determine EPC characteristics [26-29, 70]. Various markers, such as CD31, VE-cadherin, E-selectin, von Willebrand factor and eNOS, have been employed to harvest EPCs [21, 26, 28, 70, 71]. Equally solid evidence suggests that only CD34-positive EPCs isolated form umbilical cord blood or bone marrow posses the ability to differentiate into 
mature endothelial cells [25, 68, 72]. Recent studies have employed the HSC specific AC133 surface marker to isolate EPCs [26, 29]. Double labeling with CD34 and VEGFR2 is the marker of choice for obtaining a highly homogenous population of EPCs [26, 29, 73]. Functional profiling of EPCs is performed by counting the number of colonies formed after 7 days of culture. A colony consists of a central cluster of rounded cells with surrounding radiating thin, flat cells [21, 73-75]. These colonies express many endothelial characteristics, including CD31, VEGFR2, and Tie-2 [21, 75]. Although characterization of EPCs in cell culture remains challenging, the unique properties of these cells as described by Finkel and co-workers [68] may suffice as a starting point in delineating this novel BM cell population. This can be assessed by expression profiles, functional characteristics, and regenerative capacity, especially for promoting vasculogenesis and/or vascular homeostasis [68].

\section{Making the Correct STEPS in Designing the Experiments}

After confirming the stem cell phenotype, the optimal cell transplantation regimen should be examined. When designing an experimental model, the research design should closely approximate the envisioned clinical application. Optimization of cell dose, delivery route, and timing of administration are the three most crucial factors that needed to be determined in the laboratory. Based on the optimization results obtained in the laboratory, the next critical step is to determine whether these factors are feasible in the clinical setting. For instance, if stereotaxic transplantation of cells immediately following stroke was found to be a prerequisite for therapeutic benefit, then such intervention is obviously limited to patients who are able to reach a medical center with neurosurgical service. The delivery of cells via the periphery may likely require the need for chemotaxic signaling between the host ischemic brain and the transplanted cells, a scenario that may best benefit the acute or sub-acute phase of stroke rather than the stable, chronic stage when the chemokines/ cytokines acting as cues for cell migration may not be that upregulated. With this in mind, EPCs are crucial for vasculogenesis and angiogenesis, thus potentially facilitating BBB repair post-ischemic injury. Accordingly, it is critical to elucidate the BBB breakdown cascades after stroke in order to identify the peak period when to initiate strategies designed to abrogate further vasculature damage and retard stroke progression. These factors must be considered when designing an experimental design for clinical translation.

\section{To See is to Believe: Functional Readouts of Cell Transplants}

Next, STEPS requires that a battery of functional tests be in place to accurately define the therapeutic benefits of stem cells in stroke [3]. A series of behavioral tests following ischemic injury and EPC transplantation will likely allow for closer approximation of clinical improvement associated with this cell therapy. Somatosensory and motor deficits are well documented in the rodent model of ischemic injury $[31,75-78]$ and there is a growing trend toward the assessment of cognitive deficits. Alterations in cognitive behaviors can be assessed when cognitive areas of the brain are damaged by stroke, thus not all animals suffering from ischemic stroke, particularly the animals with localized damage sparing the hippocampus or specific areas of the basal ganglia, may not be the appropriate subjects for cognitive testing. Nonetheless, cognitive deficits may arise even when the hippocampus or other learning and memory areas are not affected by stroke, thus caution needs to be taken in delineating motor dysfunctions from cognitive impairments, as well as examining the brain region responsible for such cognitive alterations. Long term testing (i.e., at least 1 month) should be performed to elucidate whether functional recovery following cell therapy is stable or temporary. In contemplating with behavioral assessment of animals suffering stroke transplanted with EPCs, a novel aspect will be to test the hypothesis whether BBB repair can augment vasculogenesis and neurogenesis, among other neuroregenerative processes, in promoting functional recovery in stroke. Extensive behavioral testing after stroke and EPC transplantation is crucial in determining the efficacy of EPC transplantation, but also should facilitate a better understanding of mechanism of action of cell therapy (see further discussion below).

\section{What Is in a Name? Mechanisms of Action Underlying Cell Therapy}

In recent years, the US FDA has shown keen interest in the mechanism of action underlying stem cell therapy. Until now, safety and efficacy are the main parameters required by the FDA for IND applications. Evidence suggests that stroke, at least the secondary cell death, is closely associated with a wave of immunological attack upon the brain and/or its vasculature. Whether EPCs abrogate this immunological response following stroke remains uncertain. Widespread inflammatory reactions caused by stroke may trigger a cascade of events, which alter the integrity of the BBB, resulting in migration of leukocytes into the central nervous system. Leukocyte transmigration across the BBB during stroke-mediated immune processes may 
influence inter-endothelial junctional complex function leading to damage to the vascular endothelium and $\mathrm{BBB}$ breakdown. The disruption or dysfunction of the BBB may be a key initial factor in stroke pathogenesis, a key component of Manaenko and colleague's [79] hypothesis. EPCs may aid in ameliorating an immunological attack on the brain and its microvasculature by repairing the damaged BBB. Increasing the integrity of the BBB post-ischemic injury may aid in halting the progression of stroke pathogenesis, possibly leading to a better outcome. Thus, the study highlights the need for EPCs as transplantable cells for stroke therapy as the restoration of BBB integrity may play a critical role in preventing stroke progression.

The mechanisms of action underlying the beneficial effects of stem cells, in particular EPCs, are not fully understood. Two proposed mechanisms in which BMderived stem cells are believed to exert therapeutic benefits are through cell replacement and trophic factor secretion. Although studies utilizing BM typically focused on cell replacement therapy, the secretion of trophic factors has become an increasingly important concept in the field of cell therapy. Trophic factors help promote angiogenesis and neurogenesis and may aid in rescuing the ischemic penumbra in stroke.

When translating cell therapy to the clinic, it is important to understand and identify the mechanisms of action in order to determine if there are possible safety risks to the patient. Cell signaling, secretion of growth factors, and graft-host synaptic connections may provide insights into stem cell-mediated repair of the stroke brain. Thus, targeting these pathways can then be used for the tracking and imaging of the transplanted cells. Imaging, in particular functional magnetic resonance imaging, has been utilized to determine graft response post-transplantation [80, 81]. These tools are becoming more widespread and frequent in determining the pathway, efficacy, and safety of cell transplantation in both the laboratory and the clinic.

\section{Future Directions: Stem Cell Therapy Joining Forces with Small Molecule Treatment}

The STEPS guidelines are an offshoot of the STAIR criteria. Here, we present a merger of STEPS and STAIR whereby a neuroprotective drug may be tested in the rigorous parameters of STAIR in tandem with stem cells using the STEPS guidelines. Combination therapies involving stem cells and drugs may provide a more robust stroke outcome over stand-alone treatments. As discussed above, tPA has a very narrow therapeutic window of $3 \mathrm{~h}$ after stroke onset. Furthermore, deleterious side effects of tPA, in particular bleeding and hemorrhagic transformation, can exacerbate stroke injury and counteract its benefits of reperfusion of the occluded artery. FDA-approved drugs such as albumin and minocycline (a tetracycline antibiotic) are only recently being explored in the clinic for their offtarget, neuroprotective treatments in stroke. Because tPA is already an FDA-approved drug for stroke, finding strategies designed to extend its therapeutic window is a highly logical lab-to-clinic translation of experimental therapeutics in stroke. Hence, designing studies that dovetail on tPA's safety and efficacy profile, but also recognize the drug's limitations and adverse effects may prove to be advantageous for stroke therapy. In parallel, investigations into novel neuroprotective drugs that may be efficacious beyond the 3-hour window after stroke can also benefit many stroke patients. In 2002, Watterson and colleagues [82] suggested, based on their earlier time course analysis [83] of post-ischemia activity changes in the death associated protein kinase (DAPK) and the attenuation of neurologic sequelae resulting from treatment with DAPK inhibitors during the post-injury time windows of $6 \mathrm{~h}$ or later [84], that DAPK may be a viable therapeutic target for stroke. Because of the significant unmet need in stroke for a delayed post-injury treatment schedules that might reduce longer-term neuronal loss, such neuroprotective regimens have the potential to contribute to improved outcomes in this disease. Using both in vitro and in vivo models of stroke, we recently obtained encouraging results revealing the robust neuroprotective effects of the protein kinase inhibitors targeting other events that peak during the 6-12$\mathrm{h}$ post-ischemia time window. Significant reductions in stroke-induced histological and behavioral deficits were observed compared with animals suffering stroke that received a vehicle treatment alone. Shamloo and colleagues subsequently reported neuroprotective effects of the DAPK inhibitor developed by Watterson and coworker in both in vitro and in vivo stroke models using an experimental paradigm of DAPK inhibitor treatment initiated prior to and during stroke induction [85]. More recently, Snyder and colleagues [86] demonstrated that NMDA-induced excitotoxicity of cultured neurons deficient in DANGER, a partial MAB-21 domain-containing protein that binds directly to DAPK and inhibits DAPK catalytic activity, displayed significantly greater DAPK activity and increased cell death than wild-type control cells. They also reported that DANGER-deficient mice showed significantly more severe brain damage after acute injury than control mice. Therefore, both genetic and pharmacological approaches demonstrate that conditions characterized by inhibition of DAPK activity, either hours post-ischemia when DAPK activity reaches its peak of activity or coincident with ischemia induction, protect against subsequent neuronal loss. Altogether, a growing 
body of literature and ongoing studies indicate a pivotal role for DAPK in the physiological control of neuronal survival and pathophysiological role in neuronal death that can be attenuated by selective DAPK inhibition, thereby raising interest in addressing its potential as a novel target for stroke therapeutics. We envision that the timing of therapeutic treatments in the 6-9-h period after stroke induction corresponding to the peak time point of upregulation of DAPK enzyme activity, inflammatory genes and neurotoxic proteins as a viable therapeutic time window for treatments that attenuate events contributing to the exacerbation of secondary cell death in stroke. Being cognizant of the limited therapeutic window of tPA, finding an effective treatment beyond $3 \mathrm{~h}$, such as the proposed DAPK inhibitor treatment, should greatly increase the target population of stroke patients who could benefit from this therapy. In the same vein, other neuroprotective drugs such as albumin and minocycline as well as the FDAapproved drug tPA, can be tested with stem cells using a combination of STEPS and STAIR criteria.

\section{Conclusions}

EPCs represent a population of cells critical for angiogenesis and vasculogenesis, thus they may play a critical role in BBB repair following stroke. The preclinical results have been encouraging, and the transplantation of stem cells, including EPCs, for stroke therapy is rapidly being translated into clinical trials $[87,88]$. Over the last 5 years, recommendations to better guide the successful entry of stem cell therapy into the clinic have received continuing critical assessments from meetings involving leaders from academia, industry, $\mathrm{NIH}$, and the FDA [1-3]. The mechanism of action underlying cell therapy remains to be fully determined. The optimal timing, route of injection, and dosage for EPC transplantation are also not fully understood. These persisting gaps in our knowledge should be seriously considered in order to achieve a clinically relevant estimate of the riskto-benefit ratio of cell therapy for stroke. The initiation of clinical trials implementing EPC transplantation as a therapeutic regimen for stroke needs to be preceded by systematically designed translational preclinical studies to provide rigorous inquiry into the safety and efficacy of EPCs. Future studies are also planned in combining DAPK inhibitors and stem cell transplantation for stroke therapy. With the EPCs exerting indirect anti-inflammatory effects (via repair of the BBB thereby suppressing access of the inflammatory cells to the ischemic brain) and with small molecule inhibitors also affording anti-inflammatory modulation, the combination of these two types of novel treatments may synergistically arrest a major secondary cell death process associated with stroke.
Acknowledgments The Watterson Laboratory is supported in part by NIH awards R01NS056051 and R01AG031311 and funds from the Alzheimer's Drug Discovery Foundation. Northwestern University has patented and licensed to industry novel drugs developed in the DMW laboratory. The Borlongan Laboratory is supported by James and Esther King Foundation for Biomedical Research Program, USF Signature Program in Interdisciplinary Neuroscience, SanBio Inc., Celgene Cellular Therapeutics, KMPHC, NeuralStem Inc., NIH NINDS UO15U01NS055914-04, and NIH NINDS R01NS07195601 . CVB has patents and pending patents on cell therapy.

Open Access This article is distributed under the terms of the Creative Commons Attribution Noncommercial License which permits any noncommercial use, distribution, and reproduction in any medium, provided the original author(s) and source are credited.

\section{References}

1. Borlongan CV, Chopp M, Steinberg GK, Bliss TM, Li Y, Lu M, et al. Potential of stem/progenitor cells in treating stroke: the missing steps in translating cell therapy from laboratory to clinic. Regen Med. 2008;3:249-50.

2. Chopp M, Steinberg GK, Kondziolka D, Lu M, Bliss TM, Li Y, et al. Who's in favor of translational cell therapy for stroke: STEPS forward please? Cell Transplant. 2009;18:691-3.

3. Stem Cell Therapies as an Emerging Paradigm in Stroke Participants. Stem Cell Therapies as an Emerging Paradigm in Stroke (STEPS): bridging basic and clinical science for cellular and neurogenic factor therapy in treating stroke. Stroke. 2009;40:510-5.

4. Kondziolka D, Wechsler L, Goldstein S, Meltzer C, Thulborn KR, Gebel J, et al. Transplantation of cultured human neuronal cells for patients with stroke. Neurology. 2000;55:565-9.

5. Herzog EL, Chai L, Krause DS. Plasticity of marrow-derived stem cells. Blood. 2003;102:3483-93.

6. Munoz-Elias G, Woodbury D, Black IB. Marrow stromal cells, mitosis, and neuronal differentiation: stem cell and precursor function. Stem Cells. 2003;21:437-48.

7. Hara K, Yasuhara T, Maki M, Matsukawa N, Masuda T, Yu $\mathrm{SJ}$, et al. Neural progenitor NT2N cell lines from teratocarcinoma for transplantation therapy in stroke. Prog Neurobiol. 2008;85:318-34.

8. Hess DC, Borlongan CV. Cell-based therapy in ischemic stroke. Expert Rev Neurother. 2008;8:1193-201.

9. Hess DC, Borlongan CV. Stem cells and neurological diseases. Cell Prolif. 2008;1:94-114.

10. Lapidot T, Kollet $\mathrm{O}$. The brain-bone-blood triad: traffic lights for stem-cell homing and mobilization. Hematol Am Soc Hematol Educ Program. 2010;2010:1-6.

11. Lapidot T, Dar A, Kollet O. How do stem cells find their way home? Blood. 2005;106:1901-10.

12. Nervi B, Link DC, DiPersio JF. Cytokines and hematopoietic stem cell mobilization. J Cell Biochem. 2006;99:690-70.

13. Papayannopoulou T, Scadden DT. Stem-cell ecology and stem cells in motion. Blood. 2008;111:3923-30.

14. Dar A, Kollet O, Lapidot T. Mutual, reciprocal SDF-1/CXCR4 interactions between hematopoietic and bone marrow stromal cells regulate human stem cell migration and development in NOD/ SCID chimeric mice. Exp Hematol. 2006;34:967-75.

15. Friedenstein AJ, Chailakhjan RK, Lalykina KS. The development of fibroblast colonies in monolayer cultures of guinea-pig bone marrow and spleen cells. Tissue Kinet. 1997;3:393-403.

16. Gronthos S, Simmons PJ. The biology and application of human bone marrow stromal cell precursors. J Hematother. 1996;5:15-23. 
17. Haynesworth SE, Baber MA, Caplan AI. Cell surface antigens on human marrow-derived mesenchymal cells are detected by monoclonal antibodies. Bone. 1992;13:69-80.

18. Muraglia A, Cancedda R, Quarto R. Clonal mesenchymal progenitors from human bone marrow differentiate in vitro according to a hierarchical model. J Cell Sci. 2000;113:1161-6.

19. Pereira RF, O'Hara MD, Laptev AV, Halford KW, Pollard MD, Class R, et al. Marrow stromal cells as a source of progenitor cells for nonhematopoietic tissues in transgenic mice with a phenotype of osteogenesis imperfecta. Proc Natl Acad Sci USA. 1999;95:1142-7.

20. Prockop DJ. Marrow stromal cells as stem cells for nonhematopoietic tissues. Science. 1997;276:71-4.

21. Asahara T, Murohara T, Sullivan A, Silver M, van der Zee R, Li T, et al. Isolation of putative progenitor endothelial cells for angiogenesis. Science. 1997;275:964-7.

22. Asahara T, Masuda H, Takahashi T, Kalka C, Pastore C, Silver M, et al. Bone marrow origin of endothelial progenitor cells responsible for postnatal vasculogenesis in physiological and pathological neovascularization. Circ Res. 1999;85:221-8.

23. Heissig B, Hattori K, Dias S, Friedrich M, Ferris B, Hackett NR, et al. Recruitment of stem and progenitor cells from the bone marrow niche requires MMP-9 mediated release of kit-ligand. Cell. 2002;109:625-37.

24. Lin Y, Weisdorf DJ, Solovey A, Hebbel RP. Origins of circulating endothelial cells and endothelial outgrowth from blood. J Clin Invest. 2000;105:71-7.

25. McCarty JH. Cell adhesion and signaling networks in brain neurovascular units. Curr Opin Hematol. 2009;16:209-14.

26. Lapergue B, Mohammad A, Shuaib A. Endothelial progenitor cells and cerebroascular diseases. Prog Neurobiol. 2007;83:34962 .

27. Gehling UM, Ergün S, Schumacher U, Wagener C, Pantel K, Otem $\mathrm{M}$, et al. In vitro differentiation of endothelial cells from AC133-positive progenitor cells. Blood. 2000;95:3106-12.

28. Rustemeyer P, Wittkowski W, Jurk K, Koller A. Optimized flow cytometric analysis of endothelial progenitor cells in peripheral blood. J Immunoass Immunochem. 2006;27:77-88.

29. Takahashi T, Kalka C, Masuda H, Chen D, Silver M, Kearney M, et al. Ischemia- and cytokine-induced mobilization of bone marrow-derived endothelial progenitor cells for neovascularization. Nat Med. 1999;5:434-8.

30. Kocher AA, Schuster MD, Bonaros N, Lietz K, Xiang G, Martens $\mathrm{TP}$, et al. Myocardial homing and neovascularization by human bone marrow angioblasts is regulated by IL-8/Gro CXC chemokines. J Mol Cell Cardiol. 2006;40:455-64.

31. Borlongan CV, Hadman M, Sanberg CD, Sanberg PR. Central nervous system entry of peripherally injected umbilical cord blood cells is not required for neuroprotection in stroke. Stroke. 2004;35:2385-9.

32. Bruder SP, Jaiswal N, Haynesworth SE. Growth kinetics, selfrenewal, and the osteogenic potential of purified human mesenchymal stem cells during extensive subcultivation and following cryopreservation. J Cell Biochem. 1997;64:278-94.

33. Ozawa K, Sato K, Oh I, Ozaki K, Uchibori R, Obara Y, et al. Cell and gene therapy using mesenchymal stem cells (MSCs). J Autoimmun. 2008;30:121-7.

34. Sordi V, Piemonti L. Mesenchymal stem cells as feeder cells for pancreatic islet transplants. Rev Diabetes Stud. 2010;7:132-43.

35. Hamada S, Satoh K, Hirota M, Kanno A, Umino J, Ito H, et al. The homeobox gene MSX2 determines chemosensitivity of pancreatic cancer cells via the regulation of transporter gene ABCG2. J Cell Physiol. 2011;(in press).

36. Banfi A, Muraglia A, Dozin B, Mastrogiacomo M, Cancedda R, Quarto R. Proliferation kinetics and differentiation potential of ex vivo expanded human bone marrow stromal cells: implications for their use in cell therapy. Exp Hematol. 2000;28:707-15.

37. Nemeth K, Keane-Myers A, Brown JM, Metcalfe DD, Gorham $\mathrm{JD}$, Bundoc VG, et al. Bone marrow stromal cells use TGF-beta to suppress allergic responses in a mouse model of ragweed-induced asthma. Proc Natl Acad Sci USA. 2010;107:5652-7.

38. Zimmermann S, Voss M, Kaiser S, Kapp U, Waller CF, Martens UM. Lack of telomerase activity in human mesenchymal stem cells. Leukemia. 2003;17:1146-9.

39. Wang D, Shen W, Zhang F, Chen M, Chen H, Cao K. Connexin43 promotes survival of mesenchymal stem cells in ischaemic heart. Cell Biol Int. 2010;34:415-23.

40. Liang H, Hou H, Yi W, Yang G, Gu C, Lau WB, et al. Increased expression of pigment epithelium-derived factor in aged mesenchymal stem cells impairs their therapeutic efficacy for attenuating myocardial infarction injury. Eur Heart J. 2011;(in press)

41. Ko IK, Kim BG, Awadallah A, Mikulan J, Lin P, Letterio JJ, et al. Targeting improves MSC treatment of inflammatory bowel disease. Mol Ther. 2010;18:1365-72.

42. Kobune M, Kawano Y, Ito Y, Chiba H, Nakamura K, Tsuda H, et al. Telomerized human multipotent mesenchymal cells can differentiate into hematopoietic and cobble-stone area-supporting cells. Exp Hematol. 2003;31:715-22.

43. Pochampally RR, Smith JR, Ylostalo J, Prockop DJ. Serum deprivation of human marrow stromal cells (hMSCs) selects for a subpopulation of early progenitor cells with enhanced expression of OCT-4 and other embryonic genes. Blood. 2004;103:1647-52.

44. Witherick J, Wilkins A, Scolding N, Kemp K. Mechanisms of oxidative damage in multiple sclerosis and a cell therapy approach to treatment. Autoimmune Dis. 2011, 164608.

45. Sokal EM. From hepatocytes to stem and progenitor cells for liver regenerative medicine: advances and clinical perspectives. Cell Prolif. 2011;44:39-43.

46. Kucia M, Reca R, Campbell FR, Zuba-Surma E, Majka M, Ratajczak J, et al. A population of very small embryonic-like (VSEL) CXCR4 (+) SSEA-1(+)Oct-4+ stem cells identified in adult bone marrow. Leukemia. 2006;20:857-69.

47. Zuba-Surma EK, Kucia M, Wu W, Klich I, Lillard Jr JW, Ratajczak J, et al. Very small embryonic-like stem cells are present in adult murine organs: Image Stream-based morphological analysis and distribution studies. Cytometry A. 2008;73A:1116-27.

48. Kucia M, Halasa M, Wysoczynski M, Baskiewicz-Masiul M, Moldenhawer S, Zuba-Surma E, et al. Morphological and molecular characterization of novel population of CXCR4+ SSEA-4+ Oct-4+ very small embryonic-like cells purified from human cord blood: preliminary report. Leukemia. 2007;21:297-303.

49. Bang OY, Lee JS, Lee PH, Lee G. Autologous mesenchymal stem cell transplantation in stroke patients. Ann Neurol. 2005;57:874-82.

50. Chen J, Li Y, Wang L, Lu M, Zhang X, Chopp M. Therapeutic benefit of intracerebral transplantation of bone marrow stromal cells after cerebral ischemia in rats. J Neurol Sci. 2001;189:49-57.

51. Chen J, Wang L, Zhang Z, Lu D, Lu M, Chopp M. Therapeutic benefit of intravenous administration of bone marrow stromal cells after cerebral ischemia in rats. Stroke. 2001;32:1005-11.

52. Chopp M, Li Y. Treatment of neural injury with marrow stromal cells. Lancet Neurol. 2002;1:92-100.

53. Li Y, Chen J, Chopp M. Adult bone marrow transplantation after stroke in adult rats. Cell Transplant. 2001;10:31-40.

54. Li Y, Chen J, Chen XG, Wang L, Gautam SC, Xu YX, et al. Human marrow stromal cell therapy for stroke in rat: Neurotrophins and functional recovery. Neurology. 2002;59:514-23.

55. Li Y, Chen J, Zhang CL, Wang L, Lu D, Katakowski M, et al. Gliosis and brain remodeling after treatment of stroke in rats with marrow stromal cells. Glia. 2005;49:407-17. 
56. Rempe DA, Kent TA. Using bone marrow stromal cells for treatment of stroke. Neurology. 2002;59:486-7.

57. Song S, Kamath S, Mosquera D, Zigova T, Sanberg P, Vesely DL, et al. Expression of brain natriuretic peptide by human bone marrow stromal cells. Exp Neurol. 2004;185:191-7.

58. Tang Y, Yasuhara T, Hara K, Matsukawa N, Maki M, Yu G, et al. Transplantation of bone marrow-derived stem cells: a promising therapy for stroke. Cell Transplant. 2007;16:159-69.

59. Kucia M, Ratajczak J, Ratajczak MZ. Are bone marrow stem cells plastic or heterogenous - that is the question. Exp Hematol. 2005;33:613-23.

60. Griese DP, Ehsan A, Melo LG, Kong D, Zhang L, Mann MJ, et al. Isolation and transplantation of autologous circulating endothelial cells into denuded vessels and prosthetic grafts: Implications for cell- based vascular therapy. Circulation. 2003;108:2710-5.

61. Murohara T, Ikeda H, Duan J, Shintani S, Sasaki K, Egucji H, et al. Transplanted cord blood-derived endothelial precursor cells augment postnatal neovascularization. J Clin Invest. 2000;105:1527-36.

62. Peichev M, Naiyer AJ, Pereira D, Zhu Z, Lane WJ, Williams M, et al. Expression of VEGFR-2 and AC133 by circulating human CD34 $(+)$ cells identifies a population of functional endothelial precursors. Blood. 2000;95:952-8.

63. Rouhl RP, van Oostenbrugge RJ, Damoiseaux J, Tervaert JW, Lodder J. Endothelial progenitor cell research in stroke: a potential shift in pathophysiological and therapeutical concepts. Stroke. 2008;39:2158-65.

64. Nishimura N, Schaffer CB, Friedman B, Tsai PS, Lyden PD, Kleinfeld D. Targeted insult to subsurface cortical blood vessels using ultrashort laser pulses: three models of stroke. Nat Methods. 2006;3:99-108.

65. Rivers CS, Wardlaw JM, Armitage PA, Bastin ME, Carpenter TK, Cvoro V, et al. Persistent infarct hyperintensity on diffusionweighted imaging late after stroke indicates heterogeneous, delayed, infarct evolution. Stroke. 2006;37:1418-23.

66. Ay H, Arsava EM, Rosand J, Furie KL, Singhal AB, Schaefer PW, et al. Severity of leukoaraiosis and susceptibility to infarct growth in acute stroke. Stroke. 2008;39:1409-13.

67. Stoeckel MC, Wittsack HJ, Meisel S, Seitz RJ. Pattern of cortex and white matter involvement in severe middle cerebral artery ischemia. J Neuroimaging. 2007;17:131-40.

68. Hristov M, Weber C. Endothelial progenitor cells: characterization, pathophysiology, and possible clinical relevance. J Cell Mol Med. 2004;8:498-508.

69. Taguchi A, Matsuyama T, Moriwaki H, Hayashi T, Hayashida K, Nagatsuka $\mathrm{K}$, et al. Circulating cd34-positive cells provide an index of cerebrovascular function. Circulation. 2004;109:2972-5.

70. Ingram DA, Caplice NM, Yoder MC. Unresolved questions, changing definitions, and novel paradigms for defining endothelial progenitor cells. Blood. 2005;106:1525-31.

71. Schatteman GC, Awad O. Hemangioblasts, angioblasts, and adult endothelial cell progenitors. Anat Rec A Discov Mol Cell Evol Biol. 2004;276:13-21.

72. Khakoo AY, Finkel T. Endothelial progenitor cells. Annu Rev Med. 2005;56:79-101.
73. Cines DB, Pollak ES, Buck CA, Loscalzo J, Zimmerman GA, McEver RP, et al. Endothelial cells in physiology and in the pathophysiology of vascular disorders. Blood. 1998;91:3527-61.

74. Ghani U, Shuaib A, Salam A, Nasir A, Shuaib U, Jeerakathil T, et al. Endothelial progenitor cells during cerebrovascular disease. Stroke. 2005;36:151-3.

75. Hill JM, Zalos G, Halcox JP, Schenke WH, Waclawiw MA, Quyyumi AA, et al. Circulating endothelial progenitor cells, vascular function, and cardiovascular risk. N Engl J Med. 2003;348:593-600.

76. Borlongan CV, Skinner SJ, Geaney M, Vasconcellos AV, Elliott RB, Emerich DF. Intracerebral transplantation of porcine choroid plexus provides structural and functional neuroprotection in a rodent model of stroke. Stroke. 2004;35:2206-10.

77. Bliss TM, Kelly S, Shah AK, Foo WC, Kohli P, Stokes C, et al. Transplantation of hNT neurons into the ischemic cortex: cell survival and effect on sensorimotor behavior. J Neurosci Res. 2006;83:1004-14.

78. Chen J, Cui X, Zacharek A, Jiang H, Roberts C, Zhang C, et al. Niaspan increases angiogenesis and improves functional recovery after stroke. Ann Neurol. 2007;62:49-58.

79. Manaenko A, Chen H, Kammer J, Zhang JH, Tang J. Comparison Evans Blue injection routes: Intravenous versus intraperitoneal, for measurement of blood-brain barrier in a mice hemorrhage model. J Neurosci Methods. 2011;195:206-10.

80. Chopp M, Zhang ZG, Jiang Q. Neurogenesis, angiogenesis, and MRI indices of functional recovery from stroke. Stroke. 2007;38:827-31.

81. Guzman R, Uchida N, Bliss TM, He D, Christopherson KK, Stellwagen D, et al. Long-term monitoring of transplanted human neural stem cells in developmental and pathological contexts with MRI. Proc Natl Acad Sci USA. 2007;104:10211-6.

82. Schumacher AM, Velentza AV, Watterson DM. Death-associated protein kinase as a potential therapeutic target. Expert Opin Ther Targets. 2002;6:497-506.

83. Schumacher AM, Velentza AV, Watterson DM, Wainwright MS. DAPK catalytic activity in the hippocampus increases during the recovery phase in an animal model of brain hypoxic-ischemic injury. Biochim Biophys Acta. 2002;1600:128-37.

84. Velentza AV, Wainwright MS, Zasadzki M, Mirzoeva S, Schumacher AM, Haiech J, et al. An aminopyridazine-based inhibitor of a proapoptotic protein kinase attenuates hypoxia-ischemia induced acute brain injury. Bioorg Med Chem Lett. 2003;13:3465-70.

85. Shamloo M, Soriano L, Wieloch T, Nikolich K, Urfer R, Oksenberg D. Death-associated protein kinase is activated by dephosphorylation in response to cerebral ischemia. J Biol Chem. 2005;280:42290-9.

86. Kang BN, Ahmad AS, Saleem S, Patterson RL, Hester L, Dore S, et al. Death-associated protein kinase-mediated cell death modulated by interaction with DANGER. J Neurosci. 2010;30:93-8.

87. Borlongan $\mathrm{CV}$. Bone marrow stem cell mobilization in stroke: a 'bonehead' may be good after all! Leukemia. 2011. doi:10.1038/ leu.2011.167.

88. Borlongan CV, Glover LE, Tajiri N, Kaneko Y, Freeman TB. The great migration of bone marrow-derived stem cells toward the ischemic brain: Therapeutic implications for stroke and other neurological disorders. Prog Neurobiology. 2011;(in press). 